\title{
Hyperthermia associated with biliary obstruction during living donor liver transplantation
}

\author{
Hyeryung Kang, Joohyun Park, Jeong Jin Lee, and Gaab-Soo Kim \\ Department of Anesthesiology and Pain Medicine, Samsung Medical Center, Sungkyunkwan University School of \\ Medicine, Seoul, Korea
}

Intraoperative hypothermia occurs frequently, but hyperthermia is relatively rare during general anesthesia. We experienced a case of hyperthermia during living donor liver transplantation that appeared to be significantly associated with biliary obstruction. A 65-year-old male patient was diagnosed with intrahepatic cholangiocarcinoma, and living donor liver transplantation was planned after confirmation of no metastasis via intraoperative frozen biopsy. Following resection of a segment of common bile duct for frozen biopsy, the surgeon clamped the common bile duct, and the patient's body temperature increased gradually to $39.5^{\circ} \mathrm{C}$. As the congested bile was drained, the body temperature decreased to the normal range. This case report suggests that when a patient develops unexplained hyperthermia during hepatobiliary surgery or in a chance of biliary obstruction, clinicians should consider bile congestion as a possible reason for hyperthermia.

Keywords: Bile congestion; Biliary obstruction; Intraoperative hyperthermia; Living donor liver transplantation.

Maintenance of core body temperature (CBT) within the normal range of $36.5-37.5^{\circ} \mathrm{C}$ is a major component of homeostasis and is tightly regulated, predominantly by the hypothalamus [1]. If CBT deviates from the normal range, behavioral and autonomic thermoregulatory responses are activated in order to maintain CBT constant [2]. During general anesthesia, the aforementioned thermoregulatory mechanisms are often impaired by inhalational and intravenous anesthetics, so hypothermia is

Corresponding author: Gaab-Soo Kim, M.D., Ph.D.

Department of Anesthesiology and Pain Medicine, Samsung Medical Center, Sungkyunkwan University School of Medicine, 81, Irwon-ro, Gangnam-gu, Seoul 06351, Korea

Tel: 82-2-3410-0369, Fax: 82-2-3410-0361

Email: gskim@skku.edu

ORCID: https://orcid.org/0000-0002-9383-2652

Received: August 31, 2017.

Revised: December 1, 2017.

Accepted: December 19, 2017.

Korean J Anesthesiol 2018 August 71(4): 323-327 https://doi.org/10.4097/kja.d.18.27211 quite common. In comparison with hypothermia, intraoperative hyperthermia is less frequent but may be life-threatening, such as in case of malignant hyperthermia. More common than malignant hyperthermia is intraoperative hyperthermia with other etiologies including excessive warming, infectious fever, blood in the fourth cerebral ventricle, allergic reactions, drug toxicity, and mismatched blood transfusions [1].

We experienced an unusual case of hyperthermia during living donor liver transplantation (LDLT), and it seems plausible that the complication in this case was related to common bile duct ligation.

\section{Case Report}

A 65-year-old male patient (height: $165.2 \mathrm{~cm}$; body weight: $55 \mathrm{~kg}$ ) visited the general surgery outpatient clinic for presumptive cholangiocarcinoma. He was previously healthy with an unremarkable medical history. The patient underwent a series of preoperative evaluations. Laboratory values including complete blood cell counts (CBCs) and chemistry were within normal limits except C-reactive protein (CRP), which was elevated at

(c) This is an open-access article distributed under the terms of the Creative Commons Attribution Non-Commercial License (http://creativecommons.org/ licenses/by-nc/4.0/), which permits unrestricted non-commercial use, distribution, and reproduction in any medium, provided the original work is properly cited. 
$2.19 \mathrm{mg} / \mathrm{dl}$ (normal range: $0-0.3 \mathrm{mg} / \mathrm{dl}$ ). Total bilirubin was 0.6 $\mathrm{mg} / \mathrm{dl}$ (normal range: $0.2-1.5 \mathrm{mg} / \mathrm{dl}$ ), direct bilirubin $0.3 \mathrm{mg} /$ $\mathrm{dl}$ (normal range: $0-0.5 \mathrm{mg} / \mathrm{dl}$ ), and the patient's Model for End-Stage Liver Disease (MELD) score was 6 [3]. Vital signs were within normal limits including axillary body temperature $\left(36.7^{\circ} \mathrm{C}\right)$. Preoperative chest radiography and transthoracic echocardiography showed no abnormal findings. The imaging studies indicated a 5.1-cm-sized tumor involving both the right and left intrahepatic bile duct and common bile duct and a 2.6-cm-sized enlarged lymph node around the common hepatic artery, suggesting probable metastasis (Fig. 1). Owing to bilateral invasion of the bile duct, the tumor was unresectable. Therefore, the general surgery team planned to perform LDLT unless the patient had lymphovascular metastasis. The surgical plan was to begin the donor hepatectomy after confirming no metastasis via intraoperative frozen biopsy.

To the recipient, anesthesia was induced with intravenous thiopental sodium $350 \mathrm{mg}$, atracurium $30 \mathrm{mg}$, and sevoflurane. After endotracheal intubation, sevoflurane was used for anesthetic maintenance. Bispectral index (BIS ${ }^{\circledR}$, Medtronic, USA) was monitored, with a target intraoperative maintenance value of 40-60. The right radial artery, right femoral artery, and right femoral vein were cannulated. To prevent intraoperative hypothermia, a warming blanket (Blanketrol II ${ }^{\circledR}$, CSZ medical, USA) was applied. The ambient and warming blanket temperatures were set at 25 and $40^{\circ} \mathrm{C}$, respectively, and a fluid warming system (Level $1^{\circledR}$ H-1200 Fast Flow Fluid Warmer, Smiths Medical, USA) was also prepared. The patient's body temperature was monitored on his forehead with an infrared thermometer (FS-100 ${ }^{\circledR}$, HuBDIC, Korea) at 10-min intervals. The body temperature was initially $36.7^{\circ} \mathrm{C}$ and showed little variation until

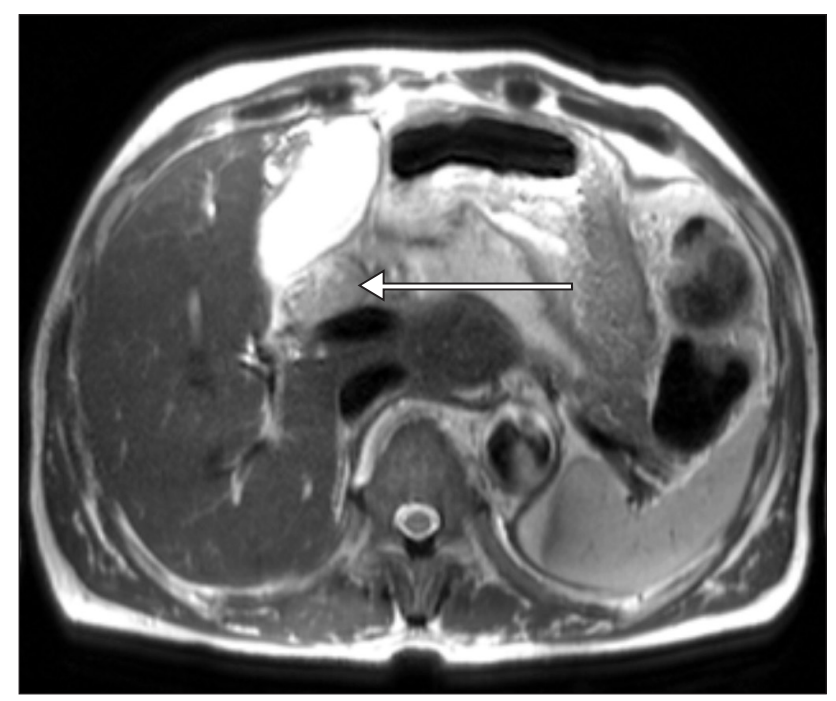

Fig. 1. MR cholangiography. Axial section shows a large tumor adjacent to the common bile duct. the operation began. After the surgeon placed the retractor, the inhalant anesthetic was changed from sevoflurane to isoflurane and anesthesia was maintained with continuous infusion of remifentanil $(0.03-0.1 \mu \mathrm{g} / \mathrm{kg} / \mathrm{min})$ and atracurium $(7 \mu \mathrm{g} / \mathrm{kg} /$ $\min$ ) [4-6]. Concentrations of the inhalant anesthetics were changed depending on the patient's hemodynamics and BIS. The sevoflurane gas was completely eliminated before reperfusion; thus, the graft was not affected. A lymph node adjacent to the common hepatic artery and a segment of the common bile duct were excised for frozen biopsy, and at this time, the surgeon clamped the common bile duct as a portion of it was resected (Fig. 2A, 09:20 am). Fortunately, both specimens were negative for cancer cells, and the LDLT was continued.

After induction of the donor, a nasogastric tube was placed and a 9 Fr AVA (Advanced Venous Access ${ }^{\circledR}$, Edward Lifesciences, USA) catheter was inserted into the right internal jugular vein of the recipient. A pulmonary artery catheter (Swan-Ganz CCOmbo $\mathrm{V}^{\circledR}$, Edward Lifesciences, USA) was inserted to monitor pulmonary artery pressure, continuous cardiac output, and mixed venous oxygen saturation. During insertion of the AVA and pulmonary artery catheter, because of the aseptic procedure, the recipient's body temperature was not measured on the forehead for half an hour, and the last recorded skin temperature was $36.9^{\circ} \mathrm{C}$ (Fig. 2B, 10:30 am). Subsequently, measurement of $\mathrm{CBT}$ with the pulmonary artery catheter was begun, and the initial CBT was $37.6^{\circ} \mathrm{C}$ (Fig. 2C, 11:00 am). The fluid warming system was turned off immediately, and the warming blanket was set to cooling mode $\left(25^{\circ} \mathrm{C}\right)$ while the room temperature was adjusted to the lowest possible setting $\left(22^{\circ} \mathrm{C}\right)$.

Donor hepatectomy was initially scheduled with a laparoscopic approach. However, mobilization of the liver was dif-

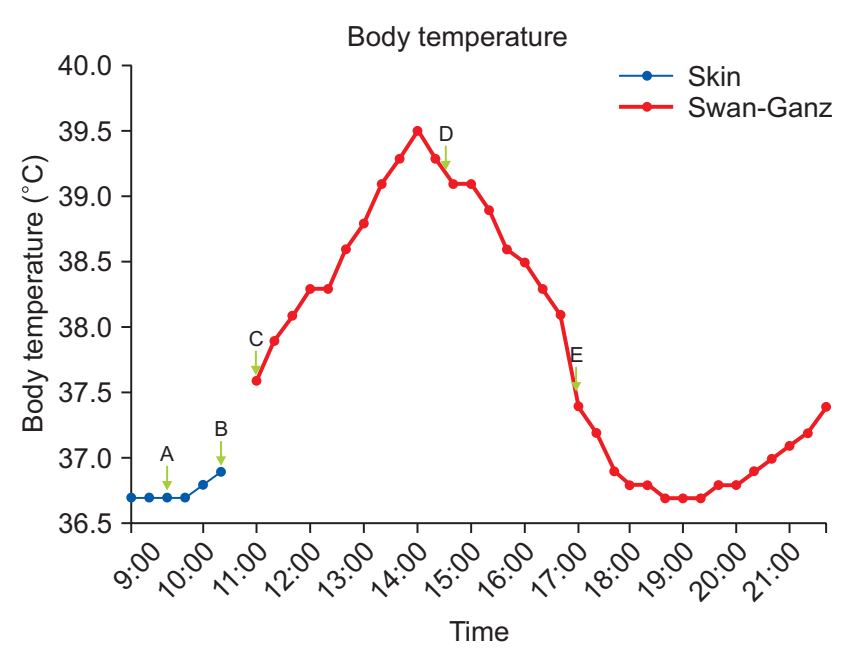

Fig. 2. Body temperature during the operation. (A) Common bile duct clamping, (B) The last recorded skin temperature, (C) Pulmonary artery catheter insertion, (D) Bile drainage, (E) Onset of anhepatic phase. 
ficult, and massive bleeding occurred from the inferior vena cava. Therefore, the laparoscopic surgery was converted to open hepatectomy. As a result, more time than usual was required to harvest the graft. During donor hepatectomy, the recipient's CBT continuously rose to $39.5^{\circ} \mathrm{C}$ despite our efforts. Vital signs and monitoring parameters including end-tidal carbon dioxide $\left(\mathrm{ETCO}_{2}\right)$ were within normal range with the exception of mild reactive tachycardia (100-110 beats/min). No blood products or medicine except anesthetics were administered. We considered the possibility of malignant hyperthermia, but there were no signs of this condition other than hyperthermia and tachycardia. $\mathrm{ETCO}_{2}$ was within the normal range (35-38 $\mathrm{mmHg}$ ), and arterial blood gas analysis showed no acidosis, hypoxemia, or hyperkalemia. Allergic reactions could be ruled out owing to the absence of skin rash. We considered device error, but the patient's skin was actually hot to the touch. In addition, his preoperative CBCs, vital signs, and chest radiographs did not show any evidence of infection, and thyroid function tests were also normal. Adequate depth of anesthesia appeared to be achieved, as BIS was monitored. We discussed the hyperthermia with the operating surgeon, and he suggested that clamping of the common bile duct could be the reason for this unexplained hyperthermia. The surgeon drained the congested bile and CBT rapidly declined (Fig. 2D, 14:30 pm). Total duration of the clamping of the bile duct was about $5 \mathrm{~h}$ (09:20 am-14:30 pm). Intraoperative bile duct clamping during an unexpectedly prolonged donor hepatectomy resulted in biliary congestion.

The anhepatic phase began $2.5 \mathrm{~h}$ after declamping of the common bile duct, at which time the recipient's CBT was $37.5^{\circ} \mathrm{C}$ (Fig. 2E, 17:00 pm). CBT decreased further to $36.9^{\circ} \mathrm{C}$ within the first hour of the anhepatic phase. We turned on the warming blanket $\left(40^{\circ} \mathrm{C}\right)$ and fluid warming system and set the room temperature at $25^{\circ} \mathrm{C}$ again. $\mathrm{CBT}$ was maintained at $36.7-37.3^{\circ} \mathrm{C}$ during the remainder of LDLT. The anesthesia time was $14 \mathrm{~h}$, and the patient received about $8,300 \mathrm{ml}$ of crystalloid, $500 \mathrm{ml}$ of colloid solution, $1,450 \mathrm{ml}$ of $5 \%$ albumin, and $248 \mathrm{ml}$ of cell saver blood, and urine output was 2,165 ml. No other blood products were transfused during the operation.

The patient was transferred to the intensive care unit, at which time body temperature at the tympanic membrane was $37.6^{\circ} \mathrm{C}$. Laboratory exams performed immediately revealed that WBC count was slightly increased compared to preoperative results $\left(9.34 \times 10^{3} / \mu \mathrm{l} \rightarrow 11.59 \times 10^{3} / \mu \mathrm{l}\right)$, in contrast to CRP $(2.19 \mathrm{mg} / \mathrm{dl} \rightarrow 2.12 \mathrm{mg} / \mathrm{dl})$. Total and direct bilirubin were also slightly increased though they were still within the normal range $(0.6 \mathrm{mg} / \mathrm{dl} \rightarrow 1.3 \mathrm{mg} / \mathrm{dl}, 0.3 \mathrm{mg} / \mathrm{dl} \rightarrow 0.9 \mathrm{mg} / \mathrm{dl}$, respectively). Postoperative chest radiographs did not show remarkable interval change since the preoperative studies. All cultures, including blood, fluid from Jackson-Pratt drains, urine, stool, throat swab, and catheter tips, showed no growth of bacteria or fungus. The patient was transferred to the general ward on the fifth postoperative day with no complications.

\section{Discussion}

Hypothermia occurs frequently during general anesthesia, especially in liver transplantation, but hyperthermia is relatively rare. Hyperthermia is defined simply as CBT exceeding the normal value $\left(>37.5^{\circ} \mathrm{C}\right)$, and this concept includes passive hyperthermia, excessive heat production, and fever [1]. Passive intraoperative hyperthermia results from excessive external heating, for example, peritoneal lavage with heated chemotherapy solutions, and is more common in infants and children than in adults [2]. Typical examples of excessive heat production that can be seen in anesthetized patients are malignant hyperthermia, thyroid storm, and light anesthesia. Fever is different from others as it is mediated by endogenous pyrogens including interleukin-1, tumor necrosis factor alpha (TNF- $\alpha$ ), interferon alpha, endothelin-1, and macrophage inflammatory protein-1, among others. Of these, primarily interleukin- 1 excites the neurons in the anterior hypothalamus and initiates thermoregulatory events by causing an increase in the production of prostaglandins, cyclic adenosine monophosphate, and nervous system monoamines, all leading to elevation of the thermoregulatory set point [7]. Intraoperative fever mostly results from local or systemic infection that is usually present in patients preoperatively, from allergic reactions due to drugs or drug fevers such as neuroleptic malignant syndrome, or from mismatched blood transfusions.

In the case presented here, the patient's body temperature increased gradually during clamping of the common bile duct, peaked at $39.5^{\circ} \mathrm{C}$, and decreased dramatically as bile was drained. As seen in Fig. 2, the elevation of the patient's body temperature was correlated with the time of bile congestion, and therefore the cause of hyperthermia in this case might have been bile congestion due to clamping of the common bile duct.

The onset of acute cholangitis requires two factors: biliary obstruction and bacterial growth in bile usually caused by bacteria ascending from the junction with the duodenum [8]. However, in this case, biliary obstruction without bacterial infection might have activated the inflammatory and febrile reactions, in a manner similar to Mirizzi syndrome, which is a rare complication of cholecystitis and chronic cholelithiasis. The syndrome is characterized by extrinsic compression of the adjacent bile duct, resulting in partial or complete obstruction of the common hepatic duct and triggering fever, obstructive jaundice, abdominal pain, and liver dysfunction [9]. Palmer et al. [10] conducted a study on pyrogenic and inflammatory properties of bile acids in human. The authors concluded that the endogenous biliary steroid, lithocholic acid, has significant pyrogenic and inflammatory action because of the aberrations in the degradation of 
cholesterol to bile acids or enteric microbial dehydroxylation of these compounds. Dillard and Bodel [11] investigated the pyrogenic activity of some endogenous steroids, including bile acids, in vitro. In accordance with the in vivo report, lithocholic acid was clearly effective in stimulating release of leukocyte pyrogen, and this may influence normal temperature regulation and contributed to clinical fever. A study by Jover et al. [12] that examined ligation of rat bile ducts showed activation of proinflammatory cytokines, TNF- $\alpha$, and interleukin-6, without fever or any obvious signs of infection and sepsis. However, the authors measured rats' body temperature only two times, the initial day of the study and three weeks later, on the rats' deathday. Therefore, it is possible that fever could not be detected because of the infrequency of body temperature measurement.

We also observed two other interesting findings in the present case. First, there was a gap between the point at which the temperature started to decline $(14: 00 \mathrm{pm})$ and the point of bile duct drainage $(14: 31 \mathrm{pm})$. The time to decline was earlier than the time to declamp. Careful investigation of this finding led us to formulate a few possibilities. First, the reason for the patient's hyperthermia was fever resulting from pyrogens owing to bile acid congestion. Therefore, CBT continued to rise until it matched the thermoregulatory set point [7]. Perhaps that point in this case was $39.5^{\circ} \mathrm{C}$. We considered this as a differential diagnosis point with malignant hyperthermia, because it would be unusual in malignant hyperthermia for the increase in CBT to stop without pharmacological treatment, and untreated malignant hyperthermia can be fatal [13]. Second, our efforts to lower CBT might have begun to show some effects. These efforts included turning off the fluid warming system, infusing room temperature fluid about at $400 \mathrm{ml} / \mathrm{h}$, switching the warming blanket to its cooling mode, maximizing the body surface exposure, and lowering the temperature of the operating room as much as possible.

The second interesting finding we observed was that the patient showed a gap in temperature between the skin of the fore- head $\left(36.9^{\circ} \mathrm{C}\right)$ and $\mathrm{CBT}\left(37.6^{\circ} \mathrm{C}\right)$. CBT can be measured at four sites: pulmonary artery, distal esophagus, tympanic membrane, or nasopharynx, and body temperatures at different sites vary markedly depending on the amount of blood flow and environmental exposure [1]. Suleman et al. [14] studied the accuracy of infrared forehead skin thermometer in 15 adult patients who reached a temperature of at least $37.8^{\circ} \mathrm{C}$ during the postoperative period. The authors reported that infrared values differed from pulmonary artery temperature by an average of $1.3 \pm 0.6^{\circ} \mathrm{C}$, and $89 \%$ of the infrared measurements differed from pulmonary artery temperature by more than $0.5^{\circ} \mathrm{C}$. However, infrared forehead skin temperature and infrared tympanic membrane temperature or mercury axillary temperature showed significant positive correlations, and the former accurately reflected the latter in another study [15]. Considering the above two studies, predicting trends in CBT with forehead skin temperature can be a reasonable approach, but it does not represent the exact value of CBT.

As previous studies [10-12] along with our case suggest, cholestasis due to clamping of the bile duct alone without microbial pathology may be correlated with the secretion and activation of pyrogenic proinflammatory cytokines, although no detailed mechanism is identified. Our case was unique in that the patient's bile duct was clamped over $5 \mathrm{~h}$ during surgery. When a patient develops hyperthermia for no apparent reason clinicians should consider bile congestion as a possible cause. Further studies are needed to reveal the exact mechanism and shed light on appropriate management.

\section{ORCID}

Hyeryung Kang, https://orcid.org/0000-0002-4241-4792

Joohyun Park, https://orcid.org/0000-0003-2429-1909

Jeong Jin Lee, https://orcid.org/0000-0003-4728-1762

Gaab-Soo Kim, https://orcid.org/0000-0002-9383-2652

\section{References}

1. Sessler DI. Temperature monitoring and perioperative thermoregulation. Anesthesiology 2008; 109: 318-38.

2. Sessler DI. Perioperative thermoregulation and heat balance. Lancet 2016; 387: 2655-64.

3. Kamath PS, Kim WR. The model for end-stage liver disease (MELD). Hepatology 2007; 45: 797-805.

4. Ko JS, Kim G, Shin YH, Gwak MS, Kim GS, Kwon CH, et al. The effects of desflurane and isoflurane on hepatic and renal functions after right hepatectomy in living donors. Transplant Proc 2012; 44: 442-4.

5. Ko JS, Gwak MS, Choi SJ, Yang M, Kim MJ, Lee JY, et al. The effects of desflurane and sevoflurane on hepatic and renal functions after right hepatectomy in living donors*. Transpl Int 2010; 23: 736-44.

6. Ko JS, Gwak MS, Choi SJ, Kim GS, Kim JA, Yang M, et al. The effects of desflurane and propofol-remifentanil on postoperative hepatic and renal functions after right hepatectomy in liver donors. Liver Transpl 2008; 14: 1150-8.

7. Patel RA, Gallagher JC. Drug fever. Pharmacotherapy 2010; 30: 57-69.

8. Kimura Y, Takada T, Strasberg SM, Pitt HA, Gouma DJ, Garden OJ, et al. TG13 current terminology, etiology, and epidemiology of acute 
cholangitis and cholecystitis. J Hepatobiliary Pancreat Sci 2013; 20: 8-23.

9. Valderrama-Treviño AI, Granados-Romero JJ, Espejel-Deloiza M, Chernitzky-Camaño J, Barrera Mera B, Estrada-Mata AG, et al. Updates in Mirizzi syndrome. Hepatobiliary Surg Nutr 2017; 6: 170-8.

10. Palmer RH, Glickman PB, Kappas A. Pyrogenic and inflammatory properties of certain bile acids in man. J Clin Invest 1962; 41: 1573-7.

11. Dillard GM, Bodel P. Studies on steroid fever. II. Pyrogenic and anti-pyrogenic activity in vitro of some endogenous steroids of man. J Clin Invest 1970; 49: 2418-26.

12. Jover R, Rodrigo R, Felipo V, Insausti R, Sáez-Valero J, García-Ayllón MS, et al. Brain edema and inflammatory activation in bile duct ligated rats with diet-induced hyperammonemia: a model of hepatic encephalopathy in cirrhosis. Hepatology 2006; 43: 1257-66.

13. Rosenberg H, Pollock N, Schiemann A, Bulger T, Stowell K. Malignant hyperthermia: a review. Orphanet J Rare Dis 2015; 10: 93.

14. Suleman MI, Doufas AG, Akça O, Ducharme M, Sessler DI. Insufficiency in a new temporal-artery thermometer for adult and pediatric patients. Anesth Analg 2002; 95: 67-71.

15. Yun KW, Lim IS. A study for accuracy and usefulness of tympanic membrane and forehead thermometers. Korean J Pediatr 2005; 48: 820-5. 